\title{
Orthodontic Treatment and Temporomandibular Disorders
}

\author{
Ticiana Sidorenko de Oliveira Capote, Silvana Regina Perez Orrico, \\ Juliana Álvares Duarte Bonini Campos, Fernanda Oliveira Bello Correa \\ and Carolina Letícia Zilli Vieira \\ Araraquara School of Dentistry, \\ São Paulo State University, UNESP \\ Brazil
}

\section{Introduction}

Temporomandibular disorders (TMD) are characterized by dysfunctions involving the muscles related to chewing, the temporomandibular joint (TMJ) and associated structures.

The most frequent symptom is pain, generally located in the chewing muscles, preauricular area and/or TMJ. In addition to pain, patients often experience limited or asymmetric mandibular movements and TMJ sounds most frequently described as snapping, cracking, gnashing or crepitating and headaches may also occur (Okeson, 1998).

Some studies have demonstrated that morphological malocclusions and occlusal interferences alone may not be considered as etiological factors for the development of TMJ dysfunctions (Vanderas, 1993; Perry, 1995). They may be considered as predisposing factors of TMD because currently psychological aspects are more associated with the appearance of the dysfunction.

However according to Mongini (1977), the occurrence of dysfunctional problems of the stomatognathic system may be related to the termination of orthodontic treatment. Other authors have demonstrated the need for occlusal therapy after termination of orthodontic treatment in order to eliminate the risk of bone reabsorption, muscular pain and TMJ disorders resulting from occlusal trauma (Salzman, 1974; Runge et al., 1989; Gianelly, 1989, Kundinger et al., 1991).

Abd Al-Hadi (1993) showed a high dependence between the frequency of TMD and malocclusion class II division I of Angle, function in group, high values of horizontal overlap and a larger number of contacts on the balancing-side. However Kahn et al. (1999), studying the relationship between occlusion and TMD, suggested the lack of any specific difference in the type of occlusal contacts that distinguish symptomatic from asymptomatic patients.

Winocur et al. (2001), assessing the contribution of some parafunctional activities in the appearance of TMD symptoms, concluded that jaw play was the characteristic most 
associated to deleterious habits and that the chronic use of chewing gum was an important contributor to noises and pain in the joints.

Considering the multifactorial etiology of TMD, its understanding, treatment and possible prevention becomes one of the greatest challenges for practitioners and their patients. So in view of the need for more studies that correlate TMD and predisposing factors, the objective of this study was to analyze the interaction among TMD, orthodontic treatment and some occlusal characteristics.

\section{Materials and methods}

The study was submitted and approved by the Human Research Ethics Committee of the Araraquara School of Dentistry, UNESP (no. 112/2000) and all patients signed an informed consent for participating in the study.

Seventy three patients were selected, 40 women and 33 men, ranging from 15 to 25 years of age and with no race distinction. Thirty six individuals had been submitted to orthodontic treatment with a fixed apparatus during periods ending from 6 months to 2 years prior to the study (experimental group). Thirty seven patients who never received orthodontic treatment had normal occlusion (control group). The selected patients had 24 to 32 completely erupted teeth with few dental restorations, no prostheses, no occlusal adjustments and no TMD treatment was conducted prior to the study.

The presence of signs and symptoms of TMD was evaluated by means of a questionnaire providing an anamnestic index (Fonseca, 1994), with a variation ranging from the absence of TMD (0 to 19), to mild TMD (20 to 44$)$, moderate TMD (45 to 69 ), and severe TMD (70 to 100).

For occlusal evaluation, contacts were analyzed in maximum habitual intercuspal position, with the odontological chair positioned at $180^{\circ}$ (lying down position) and at $90^{\circ}$ (sitting position). The contacts were marked with the aid of a film for occlusal recording.

The mandible was guided to perform lateral movements to the right and left, mapping contacts and interferences on the balancing and working-sides. The lateral disocclusion was classified as canine guidance (contact between canines on the working side, disoccluding the teeth on the balancing side), partial (contact between canines and premolars on the working side, disoccluding the teeth on the balancing side), in group (contact between canines, premolars and molars on the working side, disoccluding the teeth on the balancing side), or atypical (lateral guidance differing from those mentioned above, such as eccentric movement with disocclusion caused by the incisors and the presence of contacts on the balancing side).

All data were collected by a single previously trained and calibrated examiner and noted on an odontogram designed for this study.

\subsection{Statistical analysis}

The interaction among the variables temporomandibular disorder (TMD) (absent, present) and orthodontic treatment (Yes, No) with the variables right lateral type of disocclusion, left 
lateral type of disocclusion and gender (male, female), being assessed separately, was estimated with a log-linear analysis with a Poisson probability model.

In order to compare the average of occlusal contacts and the number of interferences, according to the absence or presence of TMD and orthodontic treatment, the two-factor Analysis of Variance was applied. The hypothesis of normality and homoscedasticity of the dependent variables were assessed by using Shapiro-Wilk's and Levene's test, respectively.

\section{Results}

Seventy-three individuals participated, from whom $54.8 \%$ were female, $50.7 \%$ had not been submitted to orthodontic treatment, and $89 \%$ presented some degree of temporomandibular disorder. The average age was $20.03+3.38$ years old.

The distribution of the participants according to gender, temporomandibular disorder and orthodontic treatment can be found in Table 1.

\begin{tabular}{lcc}
\hline Variable & \multicolumn{2}{c}{ Orthodontic Treatment } \\
Temporomandibular Disorder (TMD) & Without & With \\
Absent & $18(48.6)$ & $22(61.1)$ \\
Mild & $14(37.8)$ & $11(30.6)$ \\
Moderate & $5(13.5)$ & $3(8.3)$ \\
Gender & & \\
Male & $16(43.2)$ & $17(47.2)$ \\
Female & $21(56.8)$ & $19(52.8)$ \\
\hline
\end{tabular}

Table 1. Distribution of individuals according to gender, temporomandibular disorder and orthodontic treatment.

The interaction among the variables temporomandibular disorder (TMD) (absent TMD=0, present $\mathrm{TMD}=1$ ) and orthodontic treatment (Yes, No) with the variable right lateral type of disocclusion is shown in Table 2.

\begin{tabular}{lcccccc}
\hline \multirow{2}{*}{ Right lateral disocclusion } & \multicolumn{2}{c}{ No orthodontic treatment } & \multicolumn{3}{c}{ Orthodontic treatment } \\
& TMD=0 & TMD=1 & TMD=0 & TMD=1 & Total \\
\hline Canine & 10 & 6 & 17 & 6 & 39 \\
Partial & 2 & 4 & 3 & 1 & 10 \\
In group & 1 & 4 & - & 3 & 8 \\
Atypical & 5 & 5 & 2 & 4 & 16 \\
\hline Total & 18 & 19 & 22 & 14 & 73 \\
\hline
\end{tabular}

Table 2. Distribution of individuals according to orthodontic treatment, presence (TMD=1) or absence $(\mathrm{TMD}=0)$ of temporomandibular disorder and right lateral disocclusion.

The pattern of total independence between the variables reproduces, appropriately, the scores observed $\left(\mathrm{G}^{2}=18.153 ; \mathrm{p}=0.078\right)$. There is evidence that the variables are independent $\left(\chi^{2}=16.852 ; \mathrm{p}=0.112\right)$. 
The interaction among the variables temporomandibular disorder (TMD) (absent TMD $=0$, present $\mathrm{TMD}=1$ ) and orthodontic treatment (Yes, No) with the variable left lateral type of disocclusion is shown in Table 3.

\begin{tabular}{lccccc}
\hline Left lateral disocclusion & \multicolumn{2}{c}{ No orthodontic treatment } & \multicolumn{3}{c}{ Orthodontic Treatment } \\
& TMD=0 & TMD=1 & TMD=0 & TMD=1 & Total \\
\hline Canine & 8 & 9 & 12 & 9 & 38 \\
Partial & 3 & 2 & 5 & 1 & 11 \\
In group & 2 & 5 & 2 & 1 & 10 \\
Atypical & 5 & 3 & 3 & 3 & 14 \\
\hline Total & 18 & 19 & 22 & 14 & 73 \\
\hline
\end{tabular}

Table 3. Distribution of individuals according to orthodontic treatment, presence (TMD=1) or absence $(\mathrm{TMD}=0)$ of temporomandibular disorder and left lateral disocclusion.

In the same way as previously, the variables left lateral type of disocclusion, orthodontic treatment and temporomandibular disorder reproduce, appropriately, the scores observed $\left(G^{2}=7.534 ; p=0.674\right)$. There is evidence that the variables are independent $\left(\chi^{2}=8.083\right.$; $\mathrm{p}=0.621)$.

The interaction among the variables temporomandibular disorder (TMD) (absent TMD $=0$, present $\mathrm{TMD}=1$ ) and orthodontic treatment (Yes, No) with the variable gender is shown in Table 4.

\begin{tabular}{lccccc}
\hline Gender & \multicolumn{2}{c}{$\begin{array}{c}\text { No orthodontic treatment } \\
\text { TMD }=\mathbf{0}\end{array}$} & TMD=1 & \multicolumn{2}{c}{ Orthodontic treatment } \\
TMD $=\mathbf{0}$ & TMD=1 & Total \\
\hline Male & 9 & 7 & 9 & 8 & 33 \\
Female & 9 & 12 & 13 & 6 & 40 \\
\hline Total & 18 & 19 & 22 & 14 & 73 \\
\hline
\end{tabular}

Table 4. Distribution of individuals according to orthodontic treatment, presence (TMD=1) or absence $(\mathrm{TMD}=0)$ of temporomandibular disorder and gender.

The variables gender, orthodontic treatment and temporomandibular disorder reproduce appropriately, either, the scores observed $\left(\mathrm{G}^{2}=2.825 ; \mathrm{p}=0.588\right)$. There is evidence that the variables are independent $\left(\chi^{2}=2.778 ; p=0.596\right)$.

The interaction among the variables temporomandibular disorder (TMD) (absent TMD $=0$, present TMD=1), orthodontic treatment (Yes, No) with the variables number of contacts in sitting position, number of contacts in lying down position, age, number of occlusal interferences on the right side, number of occlusal interferences on the left side is shown in Table 5.

The individuals who were not submitted to orthodontic treatment were significantly older and showed a higher number of sitting contacts and a higher number of left lateral interferences. The individuals without TMD showed a number of sitting and lying down contacts, significantly higher than those individuals with TMD. 


\begin{tabular}{llllllll}
\hline & \multicolumn{2}{l}{ No orthodontic treatment } & \multicolumn{2}{l}{ Orthodontic treatment } & \multicolumn{2}{l}{ ANOVA (p) } & \\
Variable & TMD=0 & TMD=1 & TMD=0 & TMD=1 & ortho & TMD & interaction \\
\hline Sitting P. & $30.33 \pm 7.68$ & $21.37 \pm 6.17$ & $26.27 \pm 9.05$ & $18.29 \pm 3.43$ & 0.040 & $<0.001$ & 0.775 \\
Lying P. & $28.06 \pm 10.29$ & $18.16 \pm 8.87$ & $29.86 \pm 10.99$ & $24.64 \pm 7.50$ & 0.076 & 0.002 & 0.313 \\
Age & $21.28 \pm 2.14$ & $22.16 \pm 1.46$ & $17.64 \pm 3.66$ & $19.29 \pm 3.71$ & $<0.001$ & 0.069 & 0.577 \\
R Inter. & $0.28 \pm 0.46$ & $0.47 \pm 0.70$ & $0.18 \pm 0.39$ & $0.14 \pm 0.36$ & 0.077 & 0.511 & 0.327 \\
L Inter. & $0.44 \pm 0.62$ & $0.42 \pm 0.77$ & $0.14 \pm 0.35$ & $0.07 \pm 0.27$ & 0.013 & 0.734 & 0.873 \\
\hline
\end{tabular}

Table 5. Distribution of individuals according to orthodontic treatment, presence (TMD $=1$ ) or absence $(\mathrm{TMD}=0)$ of temporomandibular disorder, number of contacts in sitting position, number of contacts in lying down position, age, number of occlusal interferences on the right side and number of occlusal interferences on the left side.

\section{Discussion}

Many etiological factors had been related to TMD among which may be cited arthritis, tumors, congenital malformation, traumatic injuries, degenerative and neurological alterations, muscular diseases, cerebrovascular diseases, occlusal interferences and psychological aspects. According to Okeson (1998) a specific and unique etiologic factor has not been detected.

Over the years, much was discussed about the role of occlusal factors in the etiology of TMD.

Although Schwartz \& Chayes (1968) believe that dental occlusion is a secondary factor in the development of TMD, other studies (Stuart, 1964; Guichet \& Niles, 1970) have indicated occlusal interference as the primary etiological factor.

On the other hand, Mohlin \& Kopp (1978) and Seligman et al. (1988), evaluating patients regarding the presence of dysfunction and pain in the masticatory muscles, concluded that there was no significant correlation between occlusal interferences and these alterations.

To evaluate the distribution of occlusal contacts in individuals with TMD, Ciancaglini et al. (2002) developed a study with 25 students, of both genders aged 19 to 30, that presented signs and symptoms of TMD and 25 subjects in the control group. No difference was found regarding the total number, distribution and intensity of the contacts between the groups. However, intraindividual analysis demonstrated that there was a significant bilateral asymmetry in the number of contacts in both groups. Ciancaglini et al. (2003) verified the existence of a weak correlation between unilateral TMD and the number of occlusal contacts.

According to our results, the individuals without TMD showed a number of sitting and lying down contacts significantly higher than those individuals with TMD.

The importance of occlusal factors in the complex and controversial concept of TMD etiology cannot be totally neglected. Weak, but still significant associations were found between long-term development of TMD, and some malocclusions like a lateral forced bite between retruded contact position and intercuspal position, as well as unilateral crossbite, may be a potential risk factor in this respect (Egermark et al., 2003). 
The possible relationship of orthodontic treatment with signs and symptoms of TMD has also been studied lately.

He et al. (2010) verified centric relation-maximum intercuspation discrepancy in 107 pretreated orthodontic patients with signs and symptoms of TMD and concluded that this discrepancy may be a contributory factor to the development of TMD in these patients.

Karjalainen et al. (1997) evaluated 123 healthy adolescents who had undergone orthodontic treatment regarding the presence of TMD signs and symptoms. The experimental group (patients that presented signs and symptoms of TMD) received occlusal adjustment at base line and repeated every 6 months thereafter, as needed. After 3 years, $96 \%$ of the patients returned for revaluation and the number of individuals with muscular pain and signs of TMD diminished significantly in the experimental group but not in the control group. The authors concluded that a therapy of occlusal adjustment may prevent the occurrence of signs of TMD in healthy adolescents that have had orthodontic treatment.

Conti et al. (2003) evaluated the prevalence of temporomandibular disorders in 200 individuals with 9 to 20 years of age, before and after orthodontic treatment. When the TMD anamnestic index for the whole sample was considered, $34 \%$ of the subjects had mild TMD, $3.5 \%$ had moderate TMD, and $62.5 \%$ were considered TMD free. The presence and severity of TMD have not shown any relationship with type of orthodontic mechanics, so the authors concluded that orthodontic treatment was not associated with presence of signs and symptoms of TMD.

In our study, it was found $61.1 \%$ of the orthodontic treated individuals had TMD free, $30.6 \%$ had mild TMD and 8.3\% had moderate TMD. As well as in the study of Conti et al. (2003), no subjects presented severe TMD. Comparing the orthodontically treated and not treated groups according to the presence of TMD, it was observed that in both groups a higher percentage of the sample was associated with absence of TMD and with mild TMD, and no significant interaction between TMD and orthodontic treatment was verified in the different scores.

As such, recommendations concerning the need for occlusal adjustments after orthodontic therapy as a measure to prevent the appearance or aggravation of signs and symptoms of TMD are not conclusive.

In agreement with other studies (Sadowsky \& Begole, 1980; Rendell et al., 1992) no significant correlation between TMD and orthodontic treatment was verified in the different scores.

Sadowsky \& Polson (1984) reported that orthodontic treatment performed during adolescence does not generally increase or decrease the risk of developing TMD in later life. Similar results were found by Egermark et al. (2003). After a 20-year follow up of the influence of orthodontic treatment on signs and symptoms of TMDs, the authors verified that subjects who have received orthodontic treatment do not run a higher risk of developing signs and symptoms of TMD later in life.

Thus, the present study showed no difference between the orthodontically treated and nontreated groups in terms of the different TMD scores, although the treated group had not been evaluated regarding the presence or absence of TMD before orthodontic therapy. 
Other authors (Ricketts, 1966; Roth, 1973) disagree and have demonstrated that orthodontic treatment is a possible cause of TMD. Roth analyzed patients of both genders submitted to orthodontic treatment and others not submitted, regarding signs and symptoms of TMD and concluded that in the female patients who had orthodontic treatment presented a significant correlation with facial symptoms of dysfunction.

In this study, it was observed no significant interaction between gender and presence or signs and symtoms of TMD. Some authors agree (Wigdorowicz-Makowerowa et al., 1979; Ludeen et al., 1986; Abd Al-Hadi, 1993) while others (Seligman et al., 1988; Mello \& Araújo, 1997; Teixeira et al., 1999; Conti et al., 2003) demonstrate a predominance of the female over the male gender in young patients.

Abd Al-Hadi evaluated 600 asymptomatic students, of both genders ranging from 22 to 28 years of age. The authors verified a significant correlation between TMD and chewing side preference. In addition, as the number of contacts on the non-working side increased, the association with TMD also increased. Nevertheless, no association with gender was observed.

According to the results of this study, no significant interactions were found among occlusal characteristics (type of disocclusion and occlusal interferences) and TMD.

Kahn et al. evaluated the association between molar relationship, lateral movement, and nonworking side contacts with intraarticular TMD. The results demonstrated that symptomatic patients presented a higher prevalence of class II, division 1 related to the left side when compared to the control group. There was a higher prevalence of canine guidance on the right side of symptomatic patients with disk displacement. Asymptomatic patients had a higher prevalence of one or more non-working side contacts compared with symptomatic patients with normal joints and symptomatics with disc displacement. As such the authors were unable to demonstrate a relation between the characteristics studied and intraarticular TMD.

Henrikson \& Nilner (2003) observed that orthodontic treatment either with or without extractions did not increase the prevalence or worsen pre-treatment symptoms and signs of TMD, however, the authors verified that type of occlusion may play a role as a contributing factor for the development of TMD. Valle-Corotti et al. (2007) also found that some occlusal characteristics (non-working side contacts) can be factors of risk of TMD, and verified that Class III orthodontic treatment was not associated with the presence of TMD signs and symptoms.

No relationship was found between orthodontic treatment and TMD, but a positive association between TMD and parafunctional habits and reported emotional tension was verified in the study of Conti et al., 2003. According to the authors, the emotional tension is a very frequent complaint in our days, can affect general health and can predispose and cause muscle contractions and parafunctional habits, increasing the risk of initiating TMD symptoms.

It was verified no relationship between TMD and orthodontic treatment in the most of cases, but discussions are still relevant. Although the parafunctional habits and emotional factors are closely related to the etiology of TMD, occlusal characteristics can't be neglected since some studies still find occlusal risk factors for TMDs. 


\section{Conclusion}

According to the results of our study, it was observed no relationship between TMD and orthodontic treatment, and there was no interaction among TMD and characteristics such as gender, lateral type of disocclusion and number of occlusal interferences.

\section{References}

Abd Al-Hadi, L. (1993). Prevalence of temporomandibular disorders in relation to some occlusal parameters. The Journal of Prosthetic Dentistry, Vol. 70, pp.(345-350), ISSN 0022-3913

Ciancaglini, R; Gherlone, EF; Redaelli, S; Radaelli, G. (2002). The distribution of occlusal contacts in the intercuspal position and temporomandibular disorder. Journal of Oral Rehabilitation, Vol. 29, pp.(1082-1090), ISSN 0305-182X

Ciancaglini, R; Gherlone, EF; Redaelli, G. (2003). Unilateral temporomandibular disorder and asymmetry of occlusion contacts. Journal of Oral Rehabilitation, Vol. 89,pp. (180185), ISSN 0305-182X

Conti, A; Freita, M; Conti, P; Henriques, J; Janson, G. (2003). Relationship between signs and symptoms of temporomandibular disorders and orthodontic treatment: a crosssectional study. The Angle Orthodontist, Vol. 73, pp. (411-417), ISSN 0003-3219

Egermark, I; Magnusson, T; Carlsson, GE. (2003). A 20-year follow up of signs and symtoms of temporomandibular disorders and malocclusions in subjects with and without orthodontic treatment in childhood. The Angle Orthodontist, Vol. 73, pp. (109-115), ISSN 0003-3219

Fonseca, DM; Bonfante, G; Valle, AL; Freitas, SFT. (1994). Diagnóstico pela anamnese da disfunção crânio-mandibular. Revista Gaúcha de Odontologia, Vol. 42, pp. (23-28), ISSN 1981-8637

Gianelly, AA. (1989). Orthodontics, condylar position, and TMJ status. American Journal of Orthodontics and Dentofacial Orthopedics, Vol. 95, pp.(521-523). ISSN 0889-5406

Guichet, NF; Niles, F. Principle of occlusion - A collection of monographs. Denar Corporation. California: Anaheim, 1970.

He, SS; Deng, X; Wamalwa, P; Chen, S. (2010). Correlation between centric relationmaximum intercuspation discrepancy and temporomandibular joint dysfunction. Acta Odontologica Scandinavica, Vol. 68, pp. (368-376), ISSN 0001-6357

Henrikson, T; Nilner, M. (2003). Temporomandibular disorders, occlusion and orthodontic treatment. Journal of Orthodontics, Vol. 30, pp. (129-137), ISSN 1465-3125

Kahn, J; Tallents, RH; Katzberg, RW; Ross, EM; Murphy, WC. (1999). Prevalence of dental occlusal variables and intraarticular temporomandibular disorders: molar relationship, lateral guidance, and nonworking side contacts. The Journal of Prosthetic Dentistry, Vol. 82, pp. (410-415), ISSN 0022-3913

Karjalainen, M; Le Bell, Y; Jamsa, T; Karjalainen, S. (1997). Prevention of temporomandibular disorder - related signs and symptoms in orthodontically treated adolescents. Acta Odontologica Scandinavica, Vol. 55, pp. (319-324), ISSN 0001-6357

Kundinger, KK; Austin, BP; Christensen, LV; Donegan, SJ; Ferguson, DJ. (1991). An evaluation of temporomandibular joints and jaw muscles after orthodontic treatment involving premolar extractions. American Journal of Orthodontics and Dentofacial Orthopedics, Vol. 100, pp. (110-115). ISSN 0889-5406 
Lundeen, TF; Levitt, SR; McKinney, MW. (1986). Discriminative ability of the TMJ scale: age and gender differences. The Journal of Prosthetic Dentistry, Vol. 56, pp (84-92), ISSN 0022-3913

Mello, JB; Araújo, MAM. (1997). Incidência de disfunção da ATM em relação a ausência de guia anterior. Revista Odontológica do Brasil Central, Vol. 6, No.22, pp. (52-55), ISSN 1981-3708

Mohlin, B; Kopp, S. (1978). A clinical study on the relationship between malocclusion, occlusal interferences and mandibular pain and dysfunction. Swedish Dental Journal, Vol. 2, pp. (105-112), ISSN 0347-9994

Mongini, F. (1977). Anatomic and clinical evaluation of the relationship between the temporomandibular joint and occlusion. The Journal of Prosthetic Dentistry, Vol. 38, pp. (539-551), ISSN 0022-3913

Okeson, JP. Orofacial pain: guidelines for assessment, diagnosis, and management. The American Academy of Orofacial Pain. Chicago: Quintessence, 1998: 1-287.

Perry, HT. (1995). Temporomandibular joint and occlusion. The Angle Orthodontist, Vol. 46, pp. (205-214), ISSN 0003-3219

Rendell, JK; Norton, LA; Gay, T. (1992). Orthodontic treatment and temporomandibular joint disorders. American Journal of Orthodontics and Dentofacial Orthopedics, Vol. 101, pp. (84-87), ISSN 0889-5406

Ricketts, RM. (1966). Clinical implications of the temporomandibular joint. American Journal of Orthodontics, Vol. 43, pp. (136-152), ISSN 0002-9416

Roth, RH. (1973). Temporomandibular pain-dysfunction and occlusal relationships. The Angle Orthodontist, Vol. 43, pp. (136-153), ISSN 0003-3219

Runge, ME; Sadowsky, C; Sakols, EI; BeGole, EA. (1989). The relationship between temporomandibular joint sounds and malocclusion. American Journal of Orthodontics and Dentofacial Orthopedics, Vol. 96, pp. (36-42), ISSN 0889-5406

Sadowsky, C; Begole, EA. (1980). Long term status of temporomandibular joint function and functional occlusion after orthodontic treatment. American Journal of Orthodontics, Vol. 78, pp. (201-212), ISSN 0002-9416

Sadowsky, C; Polson, AM. (1984). Temporomandibular disorders and functional occlusion after orthodontic treatment: results of two long-term studies. American Journal of Orthodontics, Vol. 86, No. 5, pp. (386-390), ISSN 0002-9416

Salzman, JA. Orthodontics in daily practice, Philadelphia: Lippincott, 1974: 621-626.

Schwartz, L; Chayes, CM. (1968). Facial pain and mandibular dysfunction. W.B. Saunders Co., Philadelphia.

Seligman, DA; Pullinger, AG; Solberg, WK. (1988). Temporomandibular disorders. Part III: occlusal and articular factors associated with muscle tenderness. The Journal of Prosthetic Dentistry, Vol. 59, pp. (483-489), ISSN 0022-3913

Stuart, CE. (1964) Good occlusion for natural teeth. The Journal of Prosthetic Dentistry,Vol. 14, pp. ( 716-724), ISSN 0022-3913

Teixeira, ACB; Marcucci, G; Luz, JGC. (1999). Prevalência das maloclusões e dos índices anamnésicos e clínicos, em pacientes com disfunção da articulação temporomandibular. Revista de Odontologia Universidade de São Paulo, Vol. 13, PP. (251-256), ISSN 0103-0663 
Valle-Corotti, K; Pinzan, A; Valle, CVM; Nahás, ACR; Corotti, MV. (2007). Assessment of temporomandibular disorder and occlusion in treated class III malocclusion patients. Journal of Applied Oral Science, Vol. 15, No. 2, pp. (110-114), ISSN 1678-7757

Vanderas, AP. (1993). Relations between malocclusion and craniomandibular dysfunction in children and adolescents: a review. Pediatric Dentistry, Vol. 15, pp. (317-322), ISSN 0164-1263

Wigdorowicz-Makowerowa, N; Grodzki, G; Panek, H; Maslanka, T; Plonka, K; Palacha, A. (1979). Epidemiologic studies on prevalence and etiology of functional disturbances of the masticatory system. The Journal of Prosthetic Dentistry, Vol. 41, pp.(76-82), ISSN 0022-3913

Winocur, E; Gavish, A; Finkelstein, T; Halachmi, M; Gazit, E. (2001). Oral habits among adolescents girls and their association with symptoms of temporomandibular disorders. Journal of Oral Rehabilitation, Vol. 28, pp. (624-629), ISSN 0305-182X 


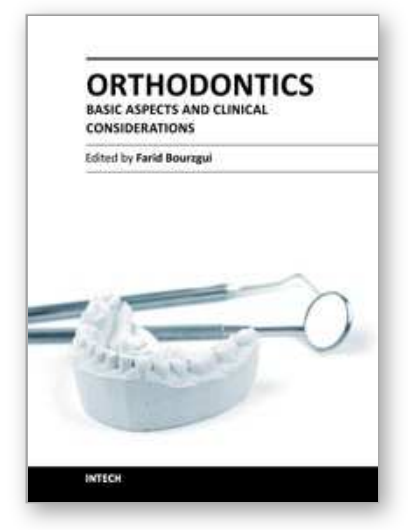

\author{
Orthodontics - Basic Aspects and Clinical Considerations \\ Edited by Prof. Farid Bourzgui
}

ISBN 978-953-51-0143-7

Hard cover, 446 pages

Publisher InTech

Published online 09, March, 2012

Published in print edition March, 2012

The book reflects the ideas of nineteen academic and research experts from different countries. The different sections of this book deal with epidemiological and preventive concepts, a demystification of cranio-mandibular dysfunction, clinical considerations and risk assessment of orthodontic treatment. It provides an overview of the state-of-the-art, outlines the experts' knowledge and their efforts to provide readers with quality content explaining new directions and emerging trends in Orthodontics. The book should be of great value to both orthodontic practitioners and to students in orthodontics, who will find learning resources in connection with their fields of study. This will help them acquire valid knowledge and excellent clinical skills.

\title{
How to reference
}

In order to correctly reference this scholarly work, feel free to copy and paste the following:

Ticiana Sidorenko de Oliveira Capote, Silvana Regina Perez Orrico, Juliana Álvares Duarte Bonini Campos, Fernanda Oliveira Bello Correa and Carolina Letícia Zilli Vieira (2012). Orthodontic Treatment and Temporomandibular Disorders, Orthodontics - Basic Aspects and Clinical Considerations, Prof. Farid Bourzgui (Ed.), ISBN: 978-953-51-0143-7, InTech, Available from: http://www.intechopen.com/books/orthodontics-basicaspects-and-clinical-considerations/orthodontic-treatment-and-temporomandibular-disorders

\section{INTECH}

open science | open minds

\section{InTech Europe}

University Campus STeP Ri

Slavka Krautzeka 83/A

51000 Rijeka, Croatia

Phone: +385 (51) 770447

Fax: +385 (51) 686166

www.intechopen.com

\section{InTech China}

Unit 405, Office Block, Hotel Equatorial Shanghai

No.65, Yan An Road (West), Shanghai, 200040, China 中国上海市延安西路65号上海国际贵都大饭店办公楼 405 单元

Phone: +86-21-62489820

Fax: +86-21-62489821 
(C) 2012 The Author(s). Licensee IntechOpen. This is an open access article distributed under the terms of the Creative Commons Attribution 3.0 License, which permits unrestricted use, distribution, and reproduction in any medium, provided the original work is properly cited. 